OPEN ACCESS

Edited by:

Vinicio De Jesus Perez,

Stanford University, United States

Reviewed by:

Sandeep Sahay,

Weill Cornell Medical College of

Cornell University, United States Roberto J. Bernardo,

University of Oklahoma, United States

*Correspondence: Yen-Chun Lai

yelai@iu.edu

Specialty section: This article was submitted to

Pulmonary Medicine,

a section of the journal

Frontiers in Medicine

Received: 05 June 2020

Accepted: 31 August 2020

Published: 07 October 2020

Citation:

Todd N and Lai Y-C (2020) Current

Understanding of Circulating

Biomarkers in Pulmonary

Hypertension Due to Left Heart

Disease. Front. Med. 7:570016.

doi: 10.3389/fmed.2020.570016

\section{Current Understanding of Circulating Biomarkers in Pulmonary Hypertension Due to Left Heart Disease}

\author{
Noah Todd ${ }^{1}$ and Yen-Chun Lai ${ }^{1,2 *}$ \\ ${ }^{1}$ Division of Pulmonary, Critical Care, Sleep and Occupational Medicine, Department of Medicine, Indiana University School \\ of Medicine, Indianapolis, IN, United States, ${ }^{2}$ Department of Anatomy, Cell Biology and Physiology, Indiana University School \\ of Medicine, Indianapolis, IN, United States
}

Pulmonary hypertension due to left heart disease (PH-LHD; Group 2), especially in the setting of heart failure with preserved ejection fraction (HFpEF), is the most frequent cause of $\mathrm{PH}$. Despite its prevalence, no effective therapies for $\mathrm{PH}$-LHD are available at present. This is largely due to the lack of a concise definition for hemodynamic phenotyping, existence of significant gaps in the understanding of the underlying pathology and the impact of associated comorbidities, as well as the absence of specific biomarkers that can aid in the early diagnosis and management of this challenging syndrome. Currently, B-type natriuretic peptide (BNP) and N-terminal proBNP (NT-proBNP) are guideline-recommended biomarkers for the diagnosis and prognosis of heart failure (HF) and PH. Endothelin-1 (ET-1), vascular endothelial growth factor-D (VEGF-D), and microRNA-206 have also been recently identified as new potential circulating biomarkers for patients with PH-LHD. In this review, we aim to present the current state of knowledge of circulating biomarkers that can be used to guide future research toward diagnosis, refine specific patient phenotype, and develop therapeutic approaches for PH-LHD, with a particular focus on $\mathrm{PH}-\mathrm{HFpEF}$. Potential circulating biomarkers identified in pre-clinical models of PH-LHD are also summarized here.

\section{Keywords: pulmonary hypertension, group $2 \mathrm{PH}, \mathrm{PH}-\mathrm{HFpEF}, \mathrm{HFpEF}$ - heart failure with preserved ejection fraction, biomarkers}

\section{INTRODUCTION}

Pulmonary hypertension due to left heart disease (PH-LHD, Group 2) is the most common cause of $\mathrm{PH}$ and is a growing public health problem with high morbidity and mortality (1-3). In fact, the presence of PH in patients with LHD has been associated with up to 5.6 times higher mortality compared to patients without PH (4). Left ventricular (LV) systolic dysfunction and diastolic dysfunction, left-sided valvular disease (aortic and mitral valve disease), and metabolic dysregulation are all known contributing factors that lead to increased LV filling pressure and the subsequent development of $\mathrm{PH}$. Among these, $\mathrm{PH}$ attributed to $\mathrm{LV}$ diastolic dysfunction, also referred to as $\mathrm{PH}$ associated with heart failure with preserved ejection fraction (PH-HFpEF), is the most common form, although the reported prevalence varies from 23 to $83 \%$ due to variable definitions and diagnostic methods used to date (5-7). In addition to the already existing ambiguity in definition of this challenging syndrome, the 6th World Symposium on PH (Nice, 2018) has 
recently redefined PH-LHD as consisting of a mean pulmonary artery pressure (mPAP) greater than $20 \mathrm{~mm} \mathrm{Hg}$ (revised from at least $25 \mathrm{~mm} \mathrm{Hg}$ ) and a pulmonary artery wedge pressure (PAWP) greater than $15 \mathrm{~mm} \mathrm{Hg}$ (Figure 1) (8-11). Although this change reflects recent reports describing increased risk of disease progression in patients with a mild elevation in MPAP (21 to $24 \mathrm{~mm} \mathrm{Hg}$ ), this revision may lead to further confusion among clinicians when trying to diagnose $\mathrm{PH}$ in patients $(9,12)$.

Abnormally elevated LV filling pressures in HFpEF, heart failure with reduced ejection fraction (HFrEF, systolic heart failure), and valvular disease can all lead to elevated left atrium (LA) pressure, increased LA volume, and reduced LA compliance $(5,13)$. Basic cellular mechanisms affecting $\mathrm{LV}$ and LA remodeling include myocyte hypertrophy, up-regulated myocardial brain/B-type natriuretic peptide (BNP) expression in the failing ventricular and atrial myocardium in response to pressure increases and/or volume overload, endothelial dysfunction, vascular oxidative stress, inflammation, interstitial fibrosis, metabolic abnormalities, etc. (14-18). Increased LA pressure can then back up into the pulmonary circulation, leading to increased pulmonary venous pressure, which is in turn transferred to pulmonary capillaries, causing damage to the alveolar-capillary barrier (also known as alveolar-capillary stress failure). As the disease progresses, structural and functional changes regulated by chronic elevation in capillary pressure may trigger pulmonary vasoconstriction, reduce nitric oxide (NO) bioavailability, increase endothelin-1 (ET-1) production, and promote remodeling in the pulmonary arteries and veins, with various combinations of intimal proliferation, medial hypertrophy, and adventitial thickening $(13,17,19-22)$. These pulmonary vascular abnormalities may then lead to a further increase in mPAP in addition to PAWP elevation, resulting in elevated right ventricular (RV) afterload and ultimately causing right-side heart failure. Depending on the extent of progressive pulmonary vascular abnormalities (also known as the precapillary component) to the underlying LHD, the backward transmission of elevated filling pressure can lead to an increase in pulmonary artery pressure proportionally (1:1 ratio) or disproportionately ( $>1: 1$ ratio) $(17,23-25)$. Patients with no significant pulmonary vasoconstriction or intrinsic pulmonary vasculopathy often exhibit proportional $\mathrm{PH}$ (isolated postcapillary $\mathrm{PH}, \mathrm{IpcPH}$ ). On the other hand, if chronically elevated LV filling pressure triggers pulmonary vasoconstriction and pathological pre-capillary remodeling to the point of having a high transpulmonary gradient (TPG, defined as mPAP-PAWP that exceeds $12 \mathrm{mmHg}$ ), elevated pulmonary vascular resistance (PVR, defined as TPG/cardiac output that exceeds 3 Wood units), and/or a high diastolic pulmonary gradient (DPG, defined as diastolic PAP-PAWP that equals or exceeds $7 \mathrm{~mm} \mathrm{Hg}$ ), patients exhibit out-of-proportion PH (combined pre-capillary and postcapillary $\mathrm{PH}, \mathrm{CpcPH}$ ). The severity of pre-capillary involvement can be established by the measured TPG, PVR, and/or DPG during right heart catheterization. In the past, $\mathrm{TPG} \leq 12 \mathrm{~mm} \mathrm{Hg}$, PVR $\leq 3$ Wood units, and/or DPG $<7 \mathrm{~mm} \mathrm{Hg}$ suggested IpcPH, and when elevated (TPG $>12 \mathrm{~mm} \mathrm{Hg}$, PVR $>3$ Wood units, and/or DPG $\geq 7 \mathrm{~mm} \mathrm{Hg}$ ), suggested CpcPH (8). These features have been associated with mortality and cardiac hospitalizations in patients with $\mathrm{CpcPH}$ associated with $\mathrm{HFpEF}$ (CpcPH-HFpEF) $(26,27)$. However, the new definition from the 6th World Symposium on PH only includes PVR of less than 3 Wood units for IpcPH and PVR of at least 3 Wood units for $\mathrm{CpcPH}$ (Figure 1) (9-11).

Despite its significant prevalence, along with high morbidity and mortality, there is no Food and Drug Administration (FDA)approved treatment for PH-LHD at present. While the use of pulmonary vasodilators has been proven to be effective in the treatment of pulmonary arterial hypertension (PAH; Group 1), the use of these agents in patients with PH-LHD has been shown to be ineffective or even harmful (see Fernandez et al. and Vachiéry et al. for recent reviews in detail) $(22,28)$. This is at least in part due to the lack of a concise and uniform definition for hemodynamic phenotyping, poor understanding of the underlying pathology and the impact of associated comorbidities, as well as the absence of specific biomarkers that can aid in the early diagnosis and management of this heterogeneous disease. Currently, BNP and N-terminal proBNP (NT-proBNP) are guideline-recommended biomarkers for the diagnosis and prognosis of HF and PH (29-31). However, these are not specific for PH-LHD and vary significantly with age, sex, body mass index (BMI), and renal function $(30,31)$. Several biomarkers have also been shown to be complimentary to the established natriuretic peptides in guiding disease management and have proven to be diagnostically valuable in distinguishing between IpcPH and $\mathrm{CpcPH}$. In this review, we aim to provide an updated overview of the current state of knowledge regarding circulating biomarkers that may be used to guide future research toward diagnosis, refinement of specific patient phenotypes and development of therapeutic approaches for PH-LHD, with a particular focus on PH-HFpEF. We will first focus on the well-established natriuretic peptides, then we will review known biomarkers proposed for $\mathrm{PAH}$ and their new roles in PH-LHD. Finally, we will highlight some of the emerging circulating biomarkers, including those identified recently in pre-clinical models of PH-LHD.

\section{WELL-ESTABLISHED BIOMARKERS: BNP AND NT-proBNP}

As LV dysfunction progresses, diastolic wall stress is the primary stimulus for myocardial BNP expression, which plays an important role in the regulation of cardiac remodeling, blood pressure, and intravascular volume (14-16). BNP is transcribed and produced primarily in the cardiomyocytes of the ventricles as prohormone proBNP, which is then cleaved into BNP (biologically active with a half-life of $20 \mathrm{~min}$ ) and its Nterminal fragment NT-proBNP (biologically inactive with a halflife of $70 \mathrm{~min}$ ). The precursor, BNP, and NT-proBNP are secreted directly into circulation in response to increased myocardial stretch mediated by pressure or volume overload (14-16).

\section{BNP/NT-proBNP in HFpEF and HFrEF}

Plasma levels of BNP and NT-proBNP are elevated in patients with $\mathrm{HF}$ and increase in proportion to the degree of LV dysfunction and the severity of symptoms of HFpEF, HFrEF, and 


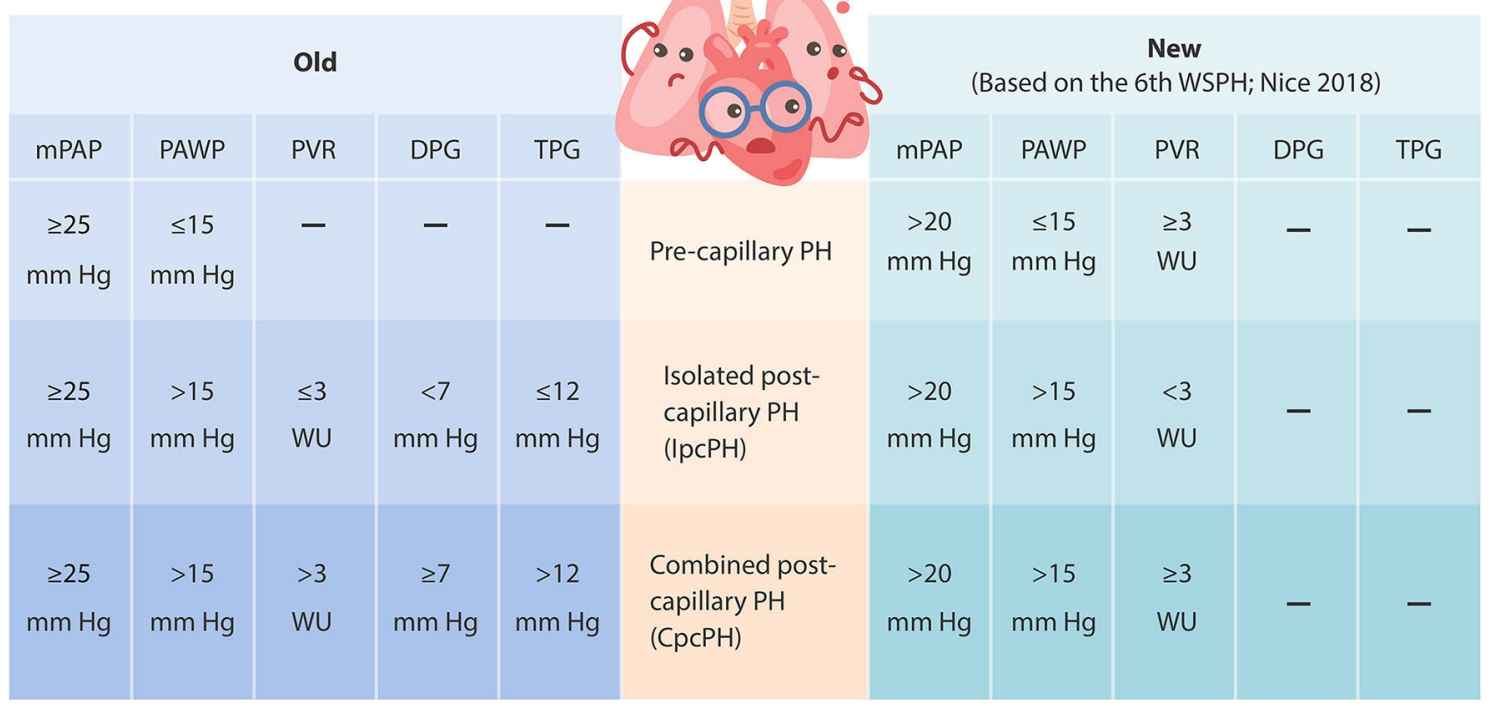

FIGURE 1 | Updated hemodynamic definition and clinical classification of pulmonary hypertension (based on the 6th World Symposium on PH, Nice 2018). mPAP, mean pulmonary artery pressure; PAWP, pulmonary artery wedge pressure; TPG, transpulmonary gradient (defined as mPAP-PAWP); PVR, pulmonary vascular resistance (defined as TPG/cardiac output); DPG, diastolic pressure gradient (defined as diastolic PAP-PAWP).

valvular disease $(15,32,33)$. In fact, BNP and NT-proBNP are among the first circulating biomarkers included in the current guidelines for the diagnosis and risk stratification of $\mathrm{HF}(8$, 31). While definitive cutoffs of BNP and NT-proBNP are not well-established for HFpEF or HFrEF (see Ponikowski et al. and Pieske et al. for the most recent recommended values) $(18,30)$, and various studies have used different thresholds, it is generally recognized that their levels are, on average, lower in HFpEF compared to $\operatorname{HFrEF}(30,33)$. This may be due to the high prevalence of obesity in HFpEF populations, as disproportionately low BNP and NT-proBNP levels have been reported in obese patients, which may be related to the mechanisms involving natriuretic peptide degradation in adipose tissue, insulin resistance, and enhanced pericardial restraint (32, 34-37). Adipocytes strongly express the natriuretic peptide receptors NPR-A and NPR-C. As BNP binds to both NPR$A$ and NPR-C, it has been suggested that increased adipose tissue can lead to more efficient clearance of BNP in obese patients. However, lower plasma NT-proBNP levels seen in patients with obesity-related HF cannot be explained by the same mechanism because NT-proBNP does not bind to NPRA or NPR-C $(38,39)$. Additionally, Obokata et al. found that patients with obesity-related HFpEF display more concentric LV remodeling, greater epicardial fat thickness, higher PAWP, $\mathrm{RV}$ dilation and dysfunction, elevated right atrial (RA) pressure, and increased total heart volume accompanied by lower NTproBNP levels compared to non-obese HFpEF patients (32). In this study, PAWP was higher for any given NT-proBNP level in patients with obesity-related HFpEF compared to non-obese HFpEF patients; however, the relationship between NT-proBNP and LV transmural pressure, defined as intracavitary pressure
(PAWP) minus the external pressure applied to the LV from pericardium and the right side of the heart (RA pressure), did not change in both obese and non-obese patients with HFpEF (32). As increased epicardial fat and higher heart volume exacerbate pericardial restraint, which may reduce wall stress as external pressure applied to the ventricle increases, these data may provide an alternative mechanism for the lower concentration of NTproBNP observed in patients with obesity-related HFpEF (32, 37). Nevertheless, even mild elevations in NT-proBNP have been found to correlate with an increased risk of HF among individuals with obesity (40).

\section{BNP/NT-proBNP in PH-HFpEF and PH-HFrEF}

Using a BNP cutoff value of $>100 \mathrm{pg} / \mathrm{ml}$, an analysis from the Northwestern University HFpEF Program reported that up to $70 \%$ of patients with confirmed HFpEF have elevated BNP, which is associated with significantly higher mPAP, RA pressure, and PVR, along with higher rates of HF hospitalization, cardiovascular hospitalization, and death compared to HFpEF patients with "normal" BNP ( $\leq 100 \mathrm{pg} / \mathrm{ml})$ (41). Elevated BNP levels were also found to be associated with an increase in PA systolic pressure (PASP) in $\mathrm{PH}$ patients associated with HFpEF, HFrEF, or valvular disease (42). Significantly higher BNP levels were observed in patients with $\mathrm{CpcPH}$ (50\% of whom have LV ejection fraction $<50 \%$ ) compared to that of patients with $\mathrm{PAH}$ (25). Similarly, CpcPH-HFpEF patients were found to have about 1.8-fold higher levels of NT-proBNP compared to IpcPH-HFpEF patients, which was associated with an increased frequency of HF hospitalizations, reduced RV-vascular coupling (as measured by the ratio between tricuspid valve annular plane systolic 
excursion and PASP; TAPSE/PASP), impaired RV function, and severely depressed exercise capacity (43). Hussain et al. reported that NT-proBNP values were overall higher in HFpEF patients with $\mathrm{PH}$, as compared to patients without $\mathrm{PH}$. NT-proBNP levels were also higher in HFpEF patients with RV dysfunction (decreased TAPSE) despite the absence of PH. A moderate negative correlation between NT-proBNP and TAPSE/PASP ratio was found in this study cohort (44). A retrospective analysis performed by Hoeper et al. in 108 patients diagnosed with $\mathrm{PH}-\mathrm{HFpEF}$ also revealed that each $100 \mathrm{ng} / \mathrm{l}$ increase in NTproBNP is associated with an increased risk of death (45). Guazzi et al. also demonstrated that NT-proBNP values were higher in non-survivors among $\mathrm{PH}-\mathrm{HFpEF}$ and $\mathrm{PH}-\mathrm{HFrEF}$ patients, as compared to survivors, although this difference was not deemed significant in the multivariate analysis of survival (46). Table 1 summarizes recent findings of BNP/NT-proBNP in PH-LHD.

In contrast, Miller et al. reported that NT-proBNP levels were lower in systemic sclerosis patients with early $\mathrm{PH}$ due to LHD than that due to PAH (47). Mazurek et al. showed that NT-proBNP levels were similar in both PH-HFpEF and $\mathrm{PAH}$ patients (48). The reason for these discrepancies is not immediately clear. While the levels of BNP and NTproBNP have not yet been compared within all $\mathrm{PH}$-patient populations and cannot yet be used to differentiate between pre-capillary and $\mathrm{PH}-\mathrm{LHD}$, the increase in circulating levels of these biomarkers appears to correlate well with the worsening of clinical outcomes, particularly in $\mathrm{PH}-\mathrm{HFpEF}$ patients. Whether or not the monitoring of either BNP or NT-proBNP would be meaningful and effective in identifying higher risk patients or in guiding specific therapy to improve outcomes in patients with PH-LHD needs to be further investigated.

\section{KNOWN BIOMARKERS ASSOCIATED WITH LHD: ET-1}

As mentioned above, chronic elevation in pulmonary capillary pressure may result in reduced pulmonary vascular compliance, structural abnormalities, and vasoconstriction in the pulmonary vasculature. Endothelial dysfunction, which leads to a reduction in NO production and an increase in ET-1 levels, is thought to be a significant contributor to these changes $(13,17,19,21,22)$. ET-1 is the most potent endogenous vasoconstrictor known at present and has been frequently reported to be elevated in patients with HFpEF, HFrEF, and left-sided valvular disease (4953). It is derived from prepro-ET-1, which is first proteolytically cleaved to yield a 39-amino acid intermediate Big ET-1, followed by a subsequent production of the 21-amino acid vasoactive peptide by endothelin converting enzymes (ECEs) (Figure 2) (54). The production and release of both Big ET-1 and ET-1 are promoted in response to increased myocardial stress, shear stress, low levels of estrogen, hyperglycemic conditions, oxidized LDL cholesterol, elevated proinflammatory cytokines, and other conditions that are commonly involved in the progression of LHD, though Big ET-1 has at least two orders of magnitude less vasoconstrictor potency than the mature ET- $1(55,56)$. ET- 1 acts at two different $\mathrm{G}$ protein-coupled receptors, $\mathrm{ET}_{\mathrm{A}}$ and $\mathrm{ET}_{\mathrm{B}}$. $\mathrm{ET}_{\mathrm{A}}$ receptors are located predominantly in vascular smooth muscle cells and myocytes, and are known for their potent and longlasting vasoconstrictive and proliferative responses to ET-1. ET $_{\mathrm{B}}$ activation, on the other hand, exerts vasoconstriction in smooth muscle cells but induces transient vasodilation in endothelial cells by releasing NO and prostacyclin. ET-1 levels were found to be increased in blood of HF patients $(51,52)$. Increased plasma levels of Big ET-1 were reported in PAH patients as well (57). Recently, Meoli et al. reported that ET-1 is higher in plasma samples collected from the wedge position of $\mathrm{CpcPH}-\mathrm{HFpEF}$ patients compared to $\mathrm{HFpEF}$ patients with IpcPH or without $\mathrm{PH}$ (58). Although the sample size was small, increased wedge plasma ET-1 concentration in this study was reported to correlate strongly with PVR in patients with $\mathrm{CpcPH}-\mathrm{HFpEF}$. A slightly larger prospective cohort study performed by Chowdhury et al. showed that regardless of being associated with $\mathrm{CpcPH}$ or $\mathrm{IpcPH}$, the wedge plasma concentration of ET-1 in PH-HFpEF patients is higher and is associated with $\mathrm{PH}, \mathrm{PVR}$, and 1-year heart failure hospitalization compared to HFpEF patients without PH (59). Similarly, Obokata et al. reported that patients with confirmed HFpEF display elevated levels of C-terminal proET-1 (CT-proET-1), a stable circulating precursor of ET-1, the magnitude of which is associated with higher pulmonary artery pressure and worse pulmonary artery compliance at rest and during exercise (52). Increased plasma CT-proET-1 levels in this study also showed high diagnostic accuracy in identifying patients with abnormal pulmonary vascular reserve during exercise. Although ET-1 may play a role in the pathophysiology of $\mathrm{PH}-\mathrm{HFpEF}$, the results of using FDA-approved endothelin receptor antagonists for the treatment of $\mathrm{PAH}$ have been rather disappointing in the treatment of patients with PH-HFpEF. The pilot study of bosentan, a dual $\mathrm{ET}_{\mathrm{A}}$ and $\mathrm{ET}_{\mathrm{B}}$ receptor antagonist, showed no signs of benefit in $\mathrm{PH}-\mathrm{HFpEF}$ patients (60). Moreover, this treatment may even be detrimental in the combined populations of $\mathrm{CpcPH}$ - and $\mathrm{IpcPH}-\mathrm{HFpEF}$ patients. Bosentan demonstrated similar harmful effects during a clinical trial for the treatment of PH-HFrEF patients (61). The MELODY1 trial, which randomized patients with $\mathrm{CpcPH}$ (> 75\% normal ejection fraction), to a 12 -week treatment with macitentan, a dual $\mathrm{ET}_{\mathrm{A}}$ and $\mathrm{ET}_{\mathrm{B}}$ receptor antagonist, or a placebo showed an increased incidence of side effects in the macitentan group (mainly fluid retention), without any major improvements in any of the exploratory endpoints (62). Currently, the SERENADE trial, a phase IIb clinical trial, is recruiting patients with HFpEF associated with pulmonary vascular disease or RV dysfunction to evaluate the long-term (24-52 weeks) treatment effect of macitentan (NCT03153111).

\section{EMERGING BIOMARKERS: VEGF-D/FIGF}

Beyond vasoconstrictive and proliferative responses mediated by ET-1, increased secretion of inflammatory cytokines and growth factors (e.g., transforming growth factor alpha 1, TGF$\alpha 1$; vascular endothelial growth factor, VEGF; and interleukin 1, IL1) have also been associated with structural and functional changes in response to the retrograde increase in pulmonary 
TABLE 1 | Collected studies of BNP/NT-proBNP in PH-LHD.

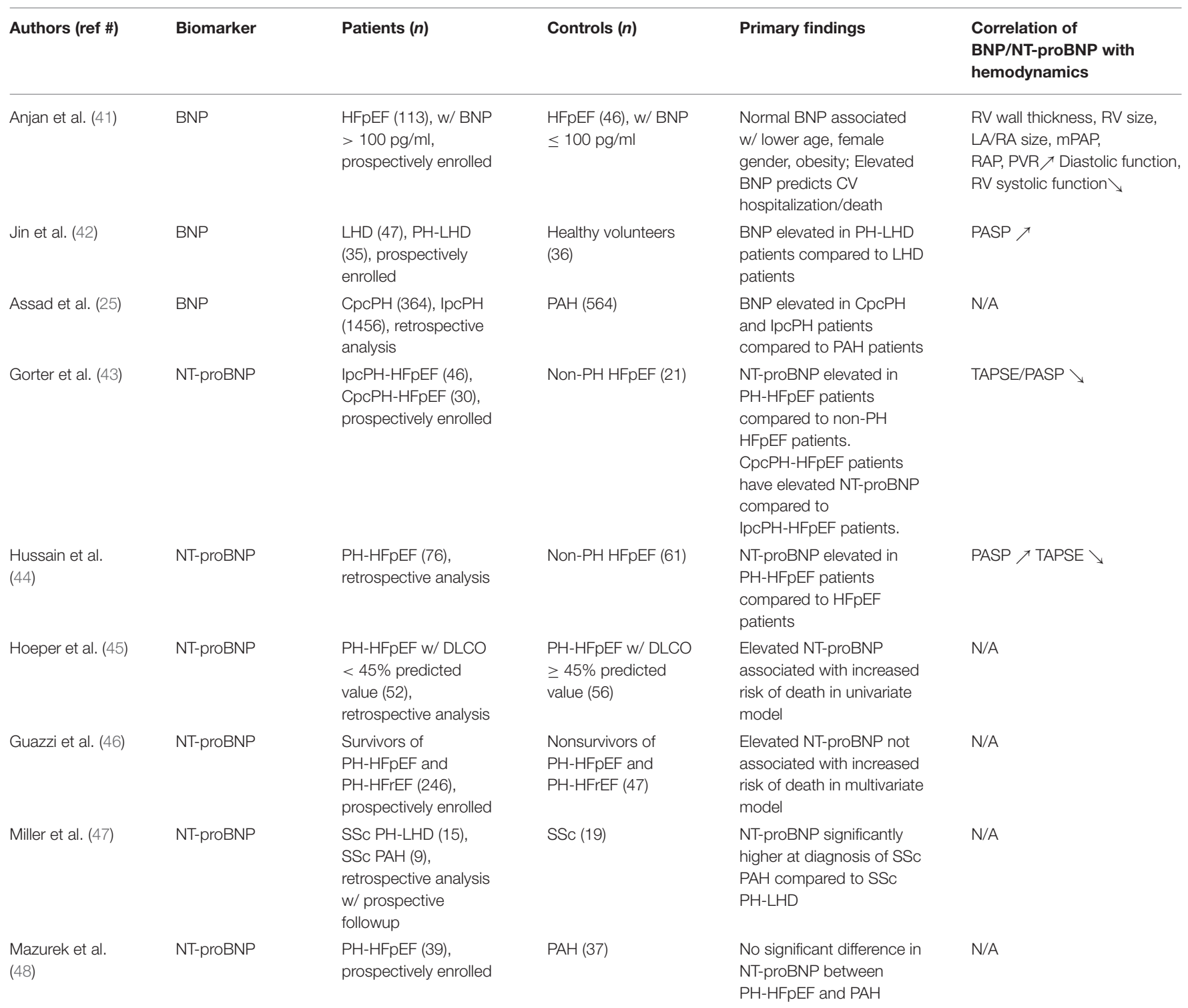

BNP, B-type natriuretic peptide; $\mathrm{CpcPH}$, combined pre- and post-capillary pulmonary hypertension; CV, cardiovascular; DLCO, diffusion capacity of the lung for carbon monoxide;

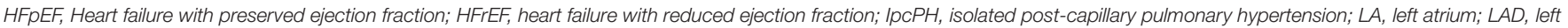

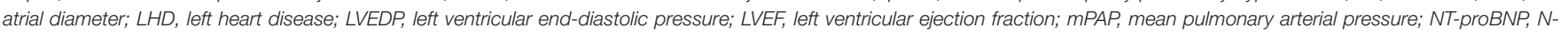

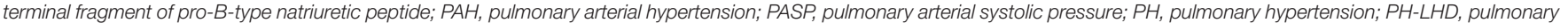

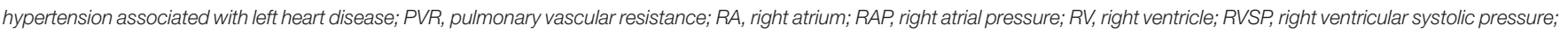

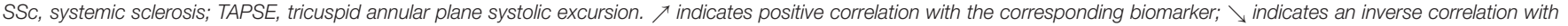
the corresponding biomarker.

capillary pressure (22). Among them, the role of vascular endothelial growth factor-D (VEGF-D) has been recently evaluated in PH-LHD. VEGF-D is a secreted factor that regulates angiogenesis, lymphangiogenesis and vascular permeability (63, 64). It is synthesized and secreted as a large precursor, which is subsequently proteolytically processed at both $\mathrm{N}$ - and C-termini to yield the mature forms. Unprocessed VEGF-D is selective for vascular endothelial growth factor receptor 3 (VEGFR-3), which is mainly expressed in lymphatic endothelial cells, whereas the mature VEGF-D activates both VEGFR-3 and VEGFR-2, the latter of which is found in both vascular and lymphatic endothelial cells (64). Besides modulating the growth of blood and lymphatic vessels, VEGF-D has been shown to induce cardiac fibrogenesis by stimulating myofibroblast growth, migration, and type I collagen synthesis (65). VEGF-D has also been shown to be up-regulated by mechanistic (formerly mammalian) target of rapamycin (mTOR), a master regulator of cell growth, proliferation, and survival that has been implicated in $\mathrm{PAH}$, lymphangioleiomyomatosis (LAM), and cancer (66). While adenoviral delivery of a gene encoding mature VEGF-D has been 


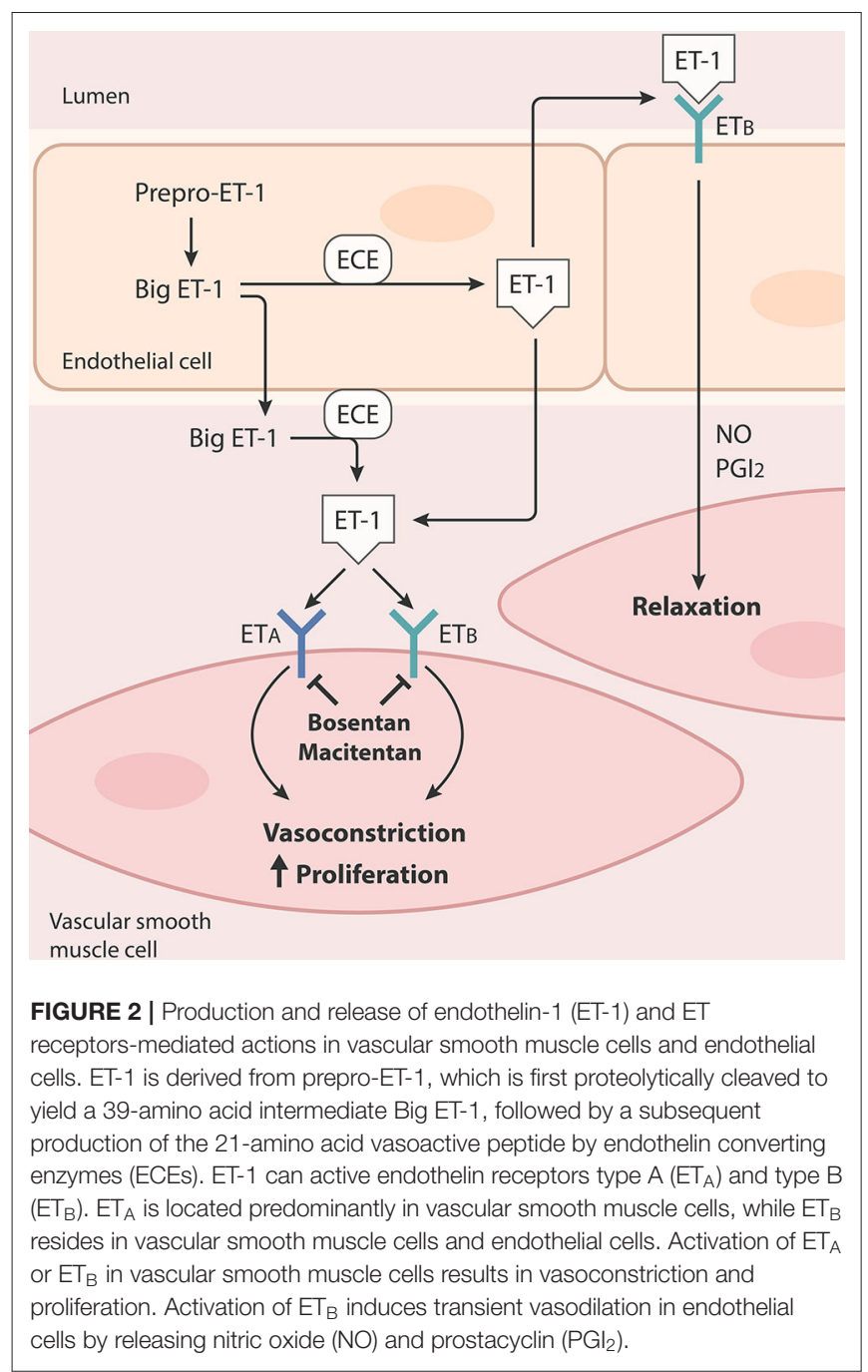

shown to improve myocardial perfusion in pigs and has now advanced through phase I/IIa studies in patients with refractory angina $(67,68)$, elevated circulating levels of VEGF-D have been reported in patients with HF, atrial fibrillation, ischemic stroke, PAH, chronic thromboembolic pulmonary hypertension (CTEPH) and LAM (69-73). Circulating VEGF-D levels were found to be higher in HF patients with pulmonary congestion (70). Elevated VEGF-D levels were also found to be a predictor of all-cause mortality in patients with coronary artery disease (CAD) and enabled differentiation of subjects with HF from patients with acute dyspnea $(70,74)$. Recently, Säleby et al. reported that VEGF-D levels were elevated in patients with PAH, CTEPH, PH-HFpEF, and PH-HFrEF compared to control subjects and HF patients without $\mathrm{PH}$, with its levels in $\mathrm{PH}$ HFrEF patients being significantly higher compared to all other etiologies of PH (72). Of note, plasma levels of VEGF-A were higher in patients with PAH, CTEPH, and PH-LHD compared to controls, although some controversy exists regarding the presence or absence of significant differences in VEGF-A between PH etiologies $(71,72)$. However, data are more consistent for
VEGF-D, showing increased levels in PH-LHD compared to PAH and CTEPH patients. Furthermore, levels of soluble fmslike tyrosine kinase 1 (sFlt-1, also known as soluble VEGFR-1 or sVEGFR-1) were significantly elevated in PH-LHD patients compared to controls, PAH, and no-PH LHD patients (71). These results are in agreement with a study by Houston et al., in which the authors showed that higher VEGF-D levels correlate with increased PAWP, reduced cardiac output, and higher BNP levels in patients with heart failure (75). A lower ejection fraction (30 \pm 18 vs. $49 \pm 22 \%$ ) was also found in subjects with higher VEGF-D levels and elevated PAWP compared to those with lower VEGF-D levels in this study cohort. While there is no data available regarding the effect of therapies targeting VEGF-D in HF, PH, and PH-LHD patients, early treatment with VEGFR3 inhibitors has been shown to improve the lumen obliteration and pulmonary pressures in Sugen/hypoxia rat models of PAH (76). Collectively, the available evidence suggests that VEGF$\mathrm{D}$ could be a potential biomarker for distinguishing PH-HFrEF from other etiologies of $\mathrm{PH}$, but this needs to be further evaluated in large multi-center studies.

\section{POTENTIAL BIOMARKERS: microRNA-206}

microRNAs (miRNAs) have been the subject of much excitement in molecular biology in the last few years. Composed of singlestranded non-coding RNAs that self-pair into a stem-and-loop structure, miRNAs act as post-transcriptional modifiers of their messenger RNA (mRNA), inducing their degradation and/or translational repression. While some controversy still exists as to their exact mechanism in identifying gene targets and roles in regulating diseases, miRNAs have emerged as promising biomarkers due to their relatively high stability (77). They can be detected extracellularly and have been implicated in a wide range of diseases. Several miRNA microarray profiling and quantitative PCR array studies have reported candidate miRNAs with potential utility as biomarkers in HF and PAH (see Fernandez et al., Wong et al., and Boucherat et al. for recent reviews in detail) $(22,78,79)$; however, only a few miRNAs have been studied in PH-LHD. Among them, circulating levels of muscle-specific miR-204 were reported to be uniquely elevated across the pulmonary vasculature in patients with $\mathrm{PAH}$, but not in patients with PH-LHD (80). On the other hand, musclespecific miR-206 levels were found to be reduced in serum of patients with PH-HFpEF, PH-HFrEF, and valvular diseaseassociated PH (42). Notably, decreased miR-206 levels in this study cohort correlated with an increase in PASP, BNP, and left atrial longitudinal diameter (LAD). In addition, the authors found that the predictive value of miR-206 in detecting $\mathrm{PH}$ in LHD was greatly improved when combined with BNP and LAD. The exact role of miR-206 in PH-LHD is currently unknown; however, reduction of miR-206 has been shown to stabilize hypoxia-inducible factor- $1 \alpha$ (HIF-1 $\alpha$ ) and to induce proliferation in cultured PASMCs $(81,82)$. In contrast, miR-206 levels were found to be elevated in lungs of rats with monocrotaline (MCT)induced PAH, and cardiac-specific overexpression of miR-206 also led to cardiac hypertrophy $(83,84)$. While the reduction of 


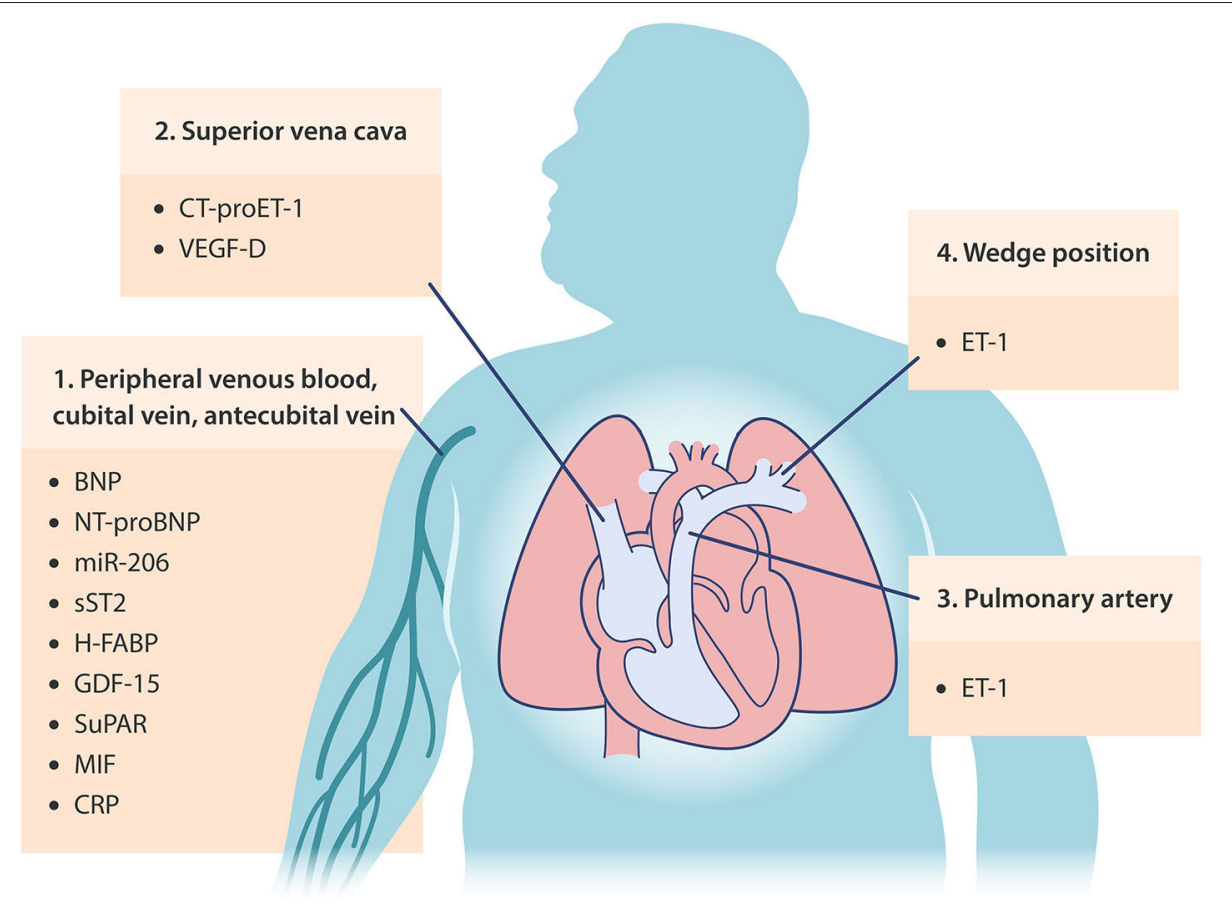

FIGURE 3 | Occurrence locations of potential circulating biomarkers in PH-LHD. BNP, brain/B-type natriuretic peptide; NT-proBNP, N-terminal proBNP; miR-206, microRNA-206; sST2, soluble suppression of tumorigenicity 2; H-FABP, heart type fatty acid binding protein; GDF-15, growth differentiation factor 15; suPAR, soluble urokinase plasminogen activator receptor; MIF, macrophage migration inhibitory factor; CRP, C-reactive protein; ET-1, endothelin-1; CT-proET-1, C-terminal pro-ET-1; VEGF-D, vascular endothelial growth factor-D.

circulating miR-206 levels may be compensated for by an increase in the intracellular miR-206 concentration, further research is needed to determine whether circulating miR-206 can be useful in the early identification of PH in LHD patients.

\section{FUTURE CANDIDATE BIOMARKERS}

In addition to the emerging biomarkers discussed above, several biomarkers of distinct processes in cardiopulmonary regulation may aid in the characterization, differentiation, and/or determination of disease management of PH-LHD (Figure 3 and Table 2). Soluble suppression of tumorigenicity 2 (sST2), also known as interleukin-1 receptor-like 1 (IL1RL1), is one such example. sST2 is a marker of mechanical stress and ventricular remodeling, which identifies patients with HFrEF and has been shown recently to be elevated in plasma of patients with Group $2 \mathrm{PH}$, compared to subjects admitted for elective coronary angiography (in whom CAD was excluded), in a single-center retrospective study performed by Mirna et al. (85). While cautious interpretation of data is needed and detailed information regarding baseline characteristics, especially for Group 2 patients, is lacking, Mirna et al. also showed that Group $2 \mathrm{PH}$ patients had higher circulating levels of growth differentiation factor 15 (GDF-15; a marker of cell injury and inflammation), heart type fatty acid binding protein $(\mathrm{H}-$ FABP; a marker of ongoing myocardial damage), and soluble urokinase plasminogen activator receptor (suPAR; a marker of ongoing inflammation) (85). In addition, higher plasma levels of macrophage migration inhibitory factor (MIF), a proinflammatory cytokine, were found to be associated with greater PASP and natriuretic peptide levels in HFpEF patients (86). Mazurek et al. also showed a trend toward higher levels of galectin-3, a beta-galactoside-binding protein which has been implicated in inflammation and fibrosis, in serum collected from pulmonary artery of patients with $\mathrm{PH}-\mathrm{HFpEF}$ relative to those with $\mathrm{PAH}$ (48). While this may be associated with greater systemic fibrosis and inflammation seen in HFpEF populations, no correlations between galectin-3 levels and any measured hemodynamic endpoints were found in PH-HFpEF or PAH patients in this study (48). The common biomarker of inflammation and cardiovascular distress, C-reactive protein (CRP), has also gained some interest as a potential biomarker of PH-LHD. Using a CRP cutoff value of $>3 \mathrm{mg} / \mathrm{dl}$, the RELAX trial reported that approximately $60 \%$ enrolled HFpEF patients have elevated CRP (87). Higher CRP levels were associated with younger age, higher BMI, COPD, atrial fibrillation, RV dysfunction, reduced exercise tolerance, higher circulating levels of ET-1, aldosterone, and NT-pro BNP. While this led the authors to conclude that high CRP levels may identify a unique HFpEF phenotype that is associated with comorbidity-driven systemic inflammation, CRP levels were not associated with $\mathrm{PH}$ or LV function in this study cohort (87). Lastly, platelets from patients with $\mathrm{PH}-\mathrm{HFpEF}$ have also been shown to exhibit a distinct metabolic phenotype compared to patients with PAH (88). 
TABLE 2 | Collected studies of future candidate biomarkers in PH-LHD.

\begin{tabular}{|c|c|c|c|c|c|}
\hline Authors (ref \#) & Biomarkers & Patients (n) & Controls (n) & Primary findings & $\begin{array}{l}\text { Correlation with } \\
\text { hemodynamics }\end{array}$ \\
\hline Mirna et al. (85) & $\begin{array}{l}\text { sST2, GDF-15, } \\
\text { H-FABP, suPAR, BNP }\end{array}$ & $\begin{array}{l}\text { Group } 1 \mathrm{PH}(13), \\
\text { Group } 2 \mathrm{PH}(35), \\
\text { Group } 3 \mathrm{PH}(7), \\
\text { Group } 4 \mathrm{PH}(12), \\
\text { Group } 5 \mathrm{PH}(19), \\
\text { retrospective analysis }\end{array}$ & $\begin{array}{l}\text { Elective coronary } \\
\text { angiography w/o } \\
\text { CAD (74) }\end{array}$ & $\begin{array}{l}\text { BNP, GDF-15, H-FABP, } \\
\text { and suPAR are elevated in } \\
\text { Group } 2 \mathrm{PH} \text { patients and } \\
\text { correlate with some } \\
\text { hemodynamic } \\
\text { measurements }\end{array}$ & 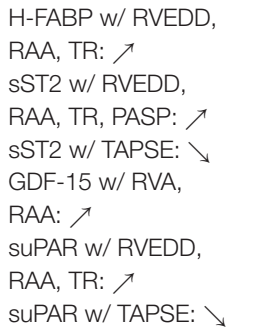 \\
\hline Luedike et al. (86) & MIF & $\begin{array}{l}\text { HFpEF w/ MIF > } \\
51.58 \mathrm{ng} / \mathrm{ml}(31) \\
\text { prospectively enrolled }\end{array}$ & $\begin{array}{l}\mathrm{HFpEF} \text { w/ MIF } \leq \\
51.58 \mathrm{ng} / \mathrm{ml}(31)\end{array}$ & $\begin{array}{l}\text { High MIF associated w/ } \\
\text { 180-day } \\
\text { mortality/hospitalization } \\
\text { and more severe HFpEF } \\
\text { symptoms }\end{array}$ & MIF w/ PASP: $\nearrow$ \\
\hline Mazurek et al. (48) & Galectin-3 & $\begin{array}{l}\text { PH-HFpEF (39), } \\
\text { prospectively enrolled }\end{array}$ & $\mathrm{PAH}(37)$ & $\begin{array}{l}\text { Galectin-3 positively } \\
\text { correlated with mortality }\end{array}$ & $\mathrm{N} / \mathrm{A}$ \\
\hline DuBrock et al. (87) & hs-CRP & $\begin{array}{l}\text { HFpEF w/ CRP }>3 \\
\text { mg/l (121), } \\
\text { retrospective analysis }\end{array}$ & $\begin{array}{l}\text { HFpEF w/ CRP } \\
\leq 3 \mathrm{mg} / \mathrm{l}(93)\end{array}$ & $\begin{array}{l}\text { High CRP associated with } \\
\text { increased comorbidity } \\
\text { burden and presence of RV } \\
\text { dysfunction }\end{array}$ & $\mathrm{N} / \mathrm{A}$ \\
\hline Nguyen et al. (88) & Platelet bioenergetics & $\begin{array}{l}\mathrm{PH}-\mathrm{HFpEF}(20) \text {, } \\
\text { retrospective analysis }\end{array}$ & $\begin{array}{l}\text { Healthy } \\
\text { volunteers (20) }\end{array}$ & $\begin{array}{l}\text { PH-HFpEF patient platelets } \\
\text { display increased maximal } \\
\text { OCR and reserve } \\
\text { respiratory capacity }\end{array}$ & \begin{tabular}{l} 
Reserve respiratory \\
capacity W/ RV SWI: \} \\
\hline
\end{tabular}
\end{tabular}

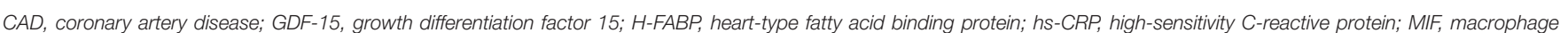

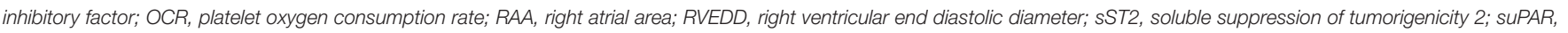

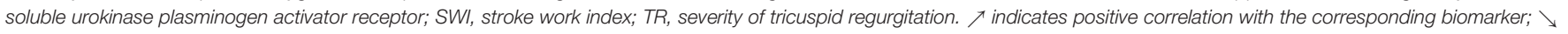
indicates an inverse correlation with the corresponding biomarker.

Unlike platelets from $\mathrm{PAH}$ patients, only an increase in maximal respiratory capacity, but not in glycolytic rate, was observed in platelets from $\mathrm{PH}-\mathrm{HFpEF}$ patients relative to healthy controls. The enhancement of platelet maximal respiratory capacity was found to be associated with RV dysfunction, but not with mPAP or PVR in patients with PH-HFpEF (88). Whether or not a measurement of these factors can provide a method for distinguishing PH-LHD patient phenotypes, identifying at-risk subjects, and predicting $\mathrm{PH}-\mathrm{LHD}$ patient outcomes requires additional research.

Apart from clinical studies, recent advances in pre-clinical models have provided new insights in the development of future biomarkers. Plasma levels of leptin, an adipokine known to induce secretion of proinflammatory cytokines and reactive oxygen species (ROS) generation, were found to be associated with $\mathrm{PH}$ severity in rats with $\mathrm{PH}-\mathrm{HFpEF}$ induced by highfat diet (HFD) in combination with supra-coronary aortic banding (SAB) and the antipsychotic olanzapine (89). Decreased plasma levels of the cardioprotective adipokine adiponectin after Sugen-mediated induction of PH-HFpEF were also observed in leptin receptor-deficient obese ZSF1 rats (90). Interestingly, metformin (the first-line drug for type 2 diabetes) was found to improve metabolic syndrome and pulmonary pressures in these models through modulation of leptin, adiponectin, as well as other mechanisms involving, at least in part, suppression of interleukin-6-associated inflammation and activation of sirtuin-3-mediated skeletal muscle glucose uptake (89, 90). Moreover, metformin has recently been shown to prevent RV dysfunction via improved insulin resistance and reduced RV lipid accumulation in HFD-treated mice (91). These findings have led to an ongoing trial designed to evaluate the effect of metformin in patients with PH-HFpEF (NCT03629340). Nitrite, a dietary precursor of $\mathrm{NO}$, has displayed similar qualities in a rat model of PH-HFpEF where it functions to increase adiponectin levels and improve skeletal muscle insulin resistance (90). A recent study by Simon et al. reported that inhalation of nitrite reduced pulmonary, RA, and pulmonary capillary wedge pressures in patients with PH-HFpEF (92). A clinical trial is now underway to examine the effect of oral nitrite in PH-HFpEF patients (NCT03015402). Moreover, therapies targeting ET-1 and NO with a Rho-kinase (ROCK) inhibitor, fasudil, have also been shown to be effective in rats with endstage $\mathrm{PH}-\mathrm{LHD}$ induced by $\mathrm{SAB}$ and in patients with $\mathrm{PH}$ HFpEF, with more favorable results in the CpcPH-HFpEF population $(93,94)$.

\section{SUMMARY AND FUTURE PERSPECTIVES}

While many challenges still exist, researchers in the field are encouraged to further expand the growing array of circulating 
biomarkers to guide future research toward facilitating screening, diagnosis, refinement of specific patient phenotypes, and development of therapeutic approaches. Consensus to concise and standardized definition for hemodynamic phenotyping is required, along with longitudinal data consisting of multiple time points and evaluation in large, multi-center studies to validate the viability of the aforementioned potential biomarkers and to explore future candidates. The ongoing PVDOMICS study supported by the National Institutes of Health/National Heart, Lung, and Blood Institute (NIH/NHLBI) may also reveal new relevant information (95). Since $\mathrm{HFpEF}$ and $\mathrm{PH}$ are recognized as multiorgan and systemic disorders $(96,97)$, the quest toward identification of meaningful extra-cardiopulmonary biomarkers may aid in providing important new insights into this clinically challenging syndrome and driving PH-LHD research forward.

\section{REFERENCES}

1. Hansdottir S, Groskreutz DJ, Gehlbach BK. WHO's in second?: a practical review of World Health Organization group 2 pulmonary hypertension. Chest. (2013) 144:638-50. doi: 10.1378/chest.12-2114

2. Strange G, Playford D, Stewart S, Deague JA, Nelson H, Kent $A$, et al. Pulmonary hypertension: prevalence and mortality in the Armadale echocardiography cohort. Heart. (2012) 98:180511. doi: 10.1136/heartjnl-2012-301992

3. Wijeratne DT, Lajkosz K, Brogly SB, Lougheed MD, Jiang L, Housin A, et al. Increasing incidence and prevalence of world health organization groups 1 to 4 pulmonary hypertension. Circ Cardiovasc Qual Outcomes. (2018) 11:e003973. doi: 10.1161/CIRCOUTCOMES.117.003973

4. Chatterjee NA, Lewis GD. What is the prognostic significance of pulmonary hypertension in heart failure? Circ Heart Fail. (2011) 4:5415. doi: 10.1161/CIRCHEARTFAILURE.111.963785

5. Vachiery JL, Adir Y, Barbera JA, Champion H, Coghlan JG, Cottin V, et al. Pulmonary hypertension due to left heart diseases. J Am Coll Cardiol. (2013) 62(Suppl. 25):D100-8. doi: 10.1016/j.jacc.2013.10.033

6. Guha A, Amione-Guerra J, Park MH. Epidemiology of pulmonary hypertension in left heart disease. Prog Cardiovasc Dis. (2016) 59:310. doi: 10.1016/j.pcad.2016.07.001

7. Levine AR, Simon MA, Gladwin MT. Pulmonary vascular disease in the setting of heart failure with preserved ejection fraction. Trends Cardiovasc Med. (2019) 29:207-17. doi: 10.1016/j.tcm.2018. 08.005

8. Galie N, Humbert M, Vachiery JL, Gibbs S, Lang I, Torbicki A, et al. 2015 ESC/ERS Guidelines for the diagnosis and treatment of pulmonary hypertension: The Joint Task Force for the Diagnosis and Treatment of Pulmonary Hypertension of the European Society of Cardiology (ESC) and the European Respiratory Society (ERS): Endorsed by: Association for European Paediatric and Congenital Cardiology (AEPC), International Society for Heart and Lung Transplantation (ISHLT). Eur Heart J. (2016) 37:67-119. doi: 10.1093/eurheartj/ehv317

9. Simonneau G, Montani D, Celermajer DS, Denton CP, Gatzoulis MA, Krowka M, et al. Haemodynamic definitions and updated clinical classification of pulmonary hypertension. Eur Respir J. (2019) 53:1801913. doi: 10.1183/13993003.01913-2018

10. Condon DF, Nickel NP, Anderson R, Mirza S, de Jesus Perez VA. The 6th World Symposium on Pulmonary Hypertension: what's old is new. F1000Res. (2019) 8:888. doi: 10.12688/f1000research.18811.1

11. Galie N, McLaughlin VV, Rubin LJ, Simonneau G. An overview of the 6th World symposium on pulmonary hypertension. Eur Respir J. (2019) 53:1802148. doi: 10.1183/13993003.02148-2018

12. Simon MA, Maron BA. Pulmonary hypertension in patients with heart failure with preserved ejection fraction. where to draw the line. Am J Respir Crit Care Med. (2019) 200:278-9. doi: 10.1164/rccm.201903-0689ED

\section{AUTHOR CONTRIBUTIONS}

NT and Y-CL wrote the article.

\section{FUNDING}

The writing of this review is supported by National Heart, Lung, and Blood Institute (R01HL142638) and American Heart Association (17SDG33400233).

\section{ACKNOWLEDGMENTS}

We thank Dr. Sergei Snovida for helpful comments on the manuscript and Elfy Chiang for assistance and production of the figures.
13. Al-Omary MS, Sugito S, Boyle AJ, Sverdlov AL, Collins NJ. Pulmonary hypertension due to left heart disease: diagnosis, pathophysiology, and therapy. Hypertension. (2020) 75:1397408. doi: 10.1161/HYPERTENSIONAHA.119.14330

14. Casaclang-Verzosa G, Gersh BJ, Tsang TS. Structural and functional remodeling of the left atrium: clinical and therapeutic implications for atrial fibrillation. J Am Coll Cardiol. (2008) 51:1-11. doi: 10.1016/j.jacc.2007.09.026

15. Bergler-Klein J, Gyongyosi M, Maurer G. The role of biomarkers in valvular heart disease: focus on natriuretic peptides. Can J Cardiol. (2014) 30:102734. doi: 10.1016/j.cjca.2014.07.014

16. Volpe M, Rubattu S, Burnett J Jr. Natriuretic peptides in cardiovascular diseases: current use and perspectives. Eur Heart J. (2014) 35:41925. doi: 10.1093/eurheartj/eht466

17. Guazzi M, Naeije R. Pulmonary hypertension in heart failure: pathophysiology, pathobiology, and emerging clinical perspectives. $J$ Am Coll Cardiol. (2017) 69:1718-34. doi: 10.1016/j.jacc.2017.01.051

18. Pieske B, Tschope C, de Boer RA, Fraser AG, Anker SD, Donal E, et al. How to diagnose heart failure with preserved ejection fraction: the HFA-PEFF diagnostic algorithm: a consensus recommendation from the Heart Failure Association (HFA) of the European Society of Cardiology (ESC). Eur Heart J. (2019) 40:3297-317. doi: 10.1093/eurheartj/ehz641

19. Borlaug BA. The pathophysiology of heart failure with preserved ejection fraction. Nat Rev Cardiol. (2014) 11:507-15. doi: 10.1038/nrcardio.2014.83

20. Rossi A, Gheorghiade M, Triposkiadis F, Solomon SD, Pieske B, Butler J. Left atrium in heart failure with preserved ejection fraction: structure, function, and significance. Circ Heart Fail. (2014) 7:1042-9. doi: 10.1161/CIRCHEARTFAILURE.114.001276

21. Dayeh NR, Ledoux J, Dupuis J. Lung capillary stress failure and arteriolar remodelling in pulmonary hypertension associated with left heart disease (Group 2 PH). Prog Cardiovasc Dis. (2016) 59:11-21. doi: 10.1016/j.pcad.2016.05.002

22. Fernandez AI, Yotti R, Gonzalez-Mansilla A, Mombiela T, Gutierrez-Ibanes E, Perez Del Villar C, et al. The biological bases of group 2 pulmonary hypertension. Int J Mol Sci. (2019) 20:5884. doi: 10.3390/ijms20235884

23. Naeije R, Vachiery JL, Yerly P, Vanderpool R. The transpulmonary pressure gradient for the diagnosis of pulmonary vascular disease. Eur Respir J. (2013) 41:217-23. doi: 10.1183/09031936.00074312

24. Assad TR, Brittain EL, Wells QS, Farber-Eger EH, Halliday SJ, Doss LN, et al. Hemodynamic evidence of vascular remodeling in combined post- and precapillary pulmonary hypertension. Pulm Circ. (2016) 6:31321. doi: $10.1086 / 688516$

25. Assad TR, Hemnes AR, Larkin EK, Glazer AM, Xu M, Wells QS, et al. Clinical and biological insights into combined post- and precapillary pulmonary hypertension. J Am Coll Cardiol. (2016) 68:252536. doi: 10.1016/j.jacc.2016.09.942

26. Gerges C, Gerges M, Lang MB, Zhang Y, Jakowitsch J, Probst P, et al. Diastolic pulmonary vascular pressure gradient: a predictor of prognosis 
in "out-of-proportion" pulmonary hypertension. Chest. (2013) 143:75866. doi: 10.1378/chest.12-1653

27. Vanderpool RR, Saul M, Nouraie M, Gladwin MT, Simon MA. Association between hemodynamic markers of pulmonary hypertension and outcomes in heart failure with preserved ejection fraction. JAMA Cardiol. (2018) 3:298306. doi: 10.1001/jamacardio.2018.0128

28. Vachiery JL, Tedford RJ, Rosenkranz S, Palazzini M, Lang I, Guazzi M, et al. Pulmonary hypertension due to left heart disease. Eur Respir J. (2019) 53:1801897. doi: 10.1183/13993003.01897-2018

29. Galie N, Humbert M, Vachiery JL, Gibbs S, Lang I, Torbicki A, et al. 2015 ESC/ERS Guidelines for the diagnosis and treatment of pulmonary hypertension: The Joint Task Force for the Diagnosis and Treatment of Pulmonary Hypertension of the European Society of Cardiology (ESC) and the European Respiratory Society (ERS): Endorsed by: Association for European Paediatric and Congenital Cardiology (AEPC), International Society for Heart and Lung Transplantation (ISHLT). Eur Respir J. (2015) 46:903-75. doi: 10.1183/13993003.01032-2015

30. Ponikowski P, Voors AA, Anker SD, Bueno H, Cleland JGF, Coats AJS, et al. 2016 ESC Guidelines for the diagnosis treatment of acute chronic heart failure: The Task Force for the diagnosis treatment of acute chronic heart failure of the European Society of Cardiology (ESC)Developed with the special contribution of the Heart Failure Association (HFA) of the ESC. Eur Heart J. (2016) 37:2129-200. doi: 10.1093/eurheartj/ehw128

31. Leuchte HH, Ten Freyhaus H, Gall H, Halank M, Hoeper MM, Kaemmerer $\mathrm{H}$, et al. Risk stratification strategy and assessment of disease progression in patients with pulmonary arterial hypertension: updated recommendations from the cologne consensus Conference 2018. Int J Cardiol. (2018) 272S:209. doi: 10.1016/j.ijcard.2018.08.084

32. Obokata M, Reddy YNV, Pislaru SV, Melenovsky V, Borlaug BA. Evidence supporting the existence of a distinct obese phenotype of heart failure with preserved ejection fraction. Circulation. (2017) 136:6-19. doi: 10.1161/CIRCULATIONAHA.116.026807

33. Gaggin HK, Januzzi JL Jr. Biomarkers and diagnostics in heart failure. Biochim Biophys Acta. (2013) 1832:2442-50. doi: 10.1016/j.bbadis.2012.12.014

34. Khan AM, Cheng S, Magnusson M, Larson MG, Newton-Cheh C, McCabe $\mathrm{EL}$, et al. Cardiac natriuretic peptides, obesity, and insulin resistance: evidence from two community-based studies. J Clin Endocrinol Metab. (2011) 96:32429. doi: $10.1210 /$ jc.2011-1182

35. Wang TJ. The natriuretic peptides and fat metabolism. N Engl J Med. (2012) 367:377-8. doi: 10.1056/NEJMcibr1204796

36. Madamanchi C, Alhosaini H, Sumida A, Runge MS. Obesity and natriuretic peptides, BNP and NT-proBNP: mechanisms and diagnostic implications for heart failure. Int J Cardiol. (2014) 176:611-7. doi: 10.1016/j.ijcard.2014.08.007

37. Borlaug BA, Reddy YNV. The Role of the Pericardium in Heart Failure: Implications for Pathophysiology and Treatment. JACC Heart Fail. (2019) 7:574-85. doi: 10.1016/j.jchf.2019.03.021

38. Nishikimi T, Nakagawa Y. Does impaired processing of pro-B-type (or brain) natriuretic peptide cause decreased plasma BNP levels in obese heart failure patients? Ann Transl Med. (2019) 7(Suppl 6):S221. doi: 10.21037/atm.2019.08.56

39. Mizuno Y, Harada E, Katoh D, Kashiwagi Y, Morikawa Y, Nakagawa $\mathrm{H}$, et al. Cardiac production of B-type natriuretic peptide is inversely related to the plasma level of free fatty acids in obese individuals possible involvement of the insulin resistance. Endocr J. (2013) 60:8795. doi: 10.1507/endocrj.EJ12-0239

40. Ndumele CE, Matsushita K, Sang Y, Lazo M, Agarwal SK, Nambi $\mathrm{V}$, et al. N-terminal pro-brain natriuretic peptide and heart failure risk among individuals with and without obesity: the Atherosclerosis Risk in Communities (ARIC) study. Circulation. (2016) 133:631-8. doi: 10.1161/CIRCULATIONAHA.115.017298

41. Anjan VY, Loftus TM, Burke MA, Akhter N, Fonarow GC, Gheorghiade M, et al. Prevalence, clinical phenotype, and outcomes associated with normal Btype natriuretic peptide levels in heart failure with preserved ejection fraction. Am J Cardiol. (2012) 110:870-6. doi: 10.1016/j.amjcard.2012.05.014

42. Jin $\mathrm{P}, \mathrm{Gu} \mathrm{W}$, Lai $\mathrm{Y}$, Zheng $\mathrm{W}$, Zhou Q, Wu X. The circulating MicroRNA-206 level predicts the severity of pulmonary hypertension in patients with left heart diseases. Cell Physiol Biochem. (2017) 41:215060. doi: $10.1159 / 000475569$
43. Gorter TM, van Veldhuisen DJ, Voors AA, Hummel YM, Lam CSP, Berger RMF, et al. Right ventricular-vascular coupling in heart failure with preserved ejection fraction and pre- vs. post-capillary pulmonary hypertension. Eur Heart J Cardiovasc Imaging. (2018) 19:425-32. doi: 10.1093/ehjci/jex133

44. Hussain I, Mohammed SF, Forfia PR, Lewis GD, Borlaug BA, Gallup DS, et al. Impaired right ventricular-pulmonary arterial coupling and effect of sildenafil in heart failure with preserved ejection fraction: an ancillary analysis from the phosphodiesterase-5 inhibition to improve clinical status and exercise capacity in diastolic heart failure (RELAX) trial. Circ Heart Fail. (2016) 9:e002729. doi: 10.1161/CIRCHEARTFAILURE.115.002729

45. Hoeper MM, Meyer K, Rademacher J, Fuge J, Welte T, Olsson KM. Diffusion capacity and mortality in patients with pulmonary hypertension due to heart failure with preserved ejection fraction. JACC Heart Fail. (2016) 4:4419. doi: 10.1016/j.jchf.2015.12.016

46. Guazzi M, Bandera F, Pelissero G, Castelvecchio S, Menicanti L, Ghio S, et al. Tricuspid annular plane systolic excursion and pulmonary arterial systolic pressure relationship in heart failure: an index of right ventricular contractile function and prognosis. Am J Physiol Heart Circ Physiol. (2013) 305:H1373-81. doi: 10.1152/ajpheart.00157.2013

47. Miller L, Chartrand S, Koenig M, Goulet JR, Rich E, Chin AS, et al. Left heart disease: a frequent cause of early pulmonary hypertension in systemic sclerosis, unrelated to elevated NT-proBNP levels or overt cardiac fibrosis but associated with increased levels of MR-proANP and MR-proADM: retrospective analysis of a French Canadian cohort. Scand J Rheumatol. (2014) 43:314-23. doi: 10.3109/03009742.2013.854407

48. Mazurek JA, Horne BD, Saeed W, Sardar MR, Zolty R. Galectin-3 levels are elevated and predictive of mortality in pulmonary hypertension. Heart Lung Circ. (2017) 26:1208-15. doi: 10.1016/j.hlc.2016.12.012

49. McMurray JJ, Ray SG, Abdullah I, Dargie HJ, Morton JJ. Plasma endothelin in chronic heart failure. Circulation. (1992) 85:1374-9. doi: 10.1161/01.CIR.85.4.1374

50. Hulsmann M, Stanek B, Frey B, Sturm B, Putz D, Kos T, et al. Value of cardiopulmonary exercise testing and big endothelin plasma levels to predict short-term prognosis of patients with chronic heart failure. J Am Coll Cardiol. (1998) 32:1695-700. doi: 10.1016/S0735-1097(98)00437-9

51. Valero-Munoz M, Li S, Wilson RM, Boldbaatar B, Iglarz M, Sam F. Dual endothelin-A/Endothelin-B receptor blockade and cardiac remodeling in heart failure with preserved ejection fraction. Circ Heart Fail. (2016) 9:e003381. doi: 10.1161/CIRCHEARTFAILURE.116.003381

52. Obokata M, Kane GC, Reddy YNV, Melenovsky V, Olson TP, Jarolim $\mathrm{P}$, et al. The neurohormonal basis of pulmonary hypertension in heart failure with preserved ejection fraction. Eur Heart J. (2019) 40:370717. doi: $10.1093 /$ eurheartj/ehz626

53. Peltonen T, Taskinen P, Napankangas J, Leskinen H, Ohtonen P, Soini Y, et al. Increase in tissue endothelin-1 and ETA receptor levels in human aortic valve stenosis. Eur Heart J. (2009) 30:242-9. doi: 10.1093/eurheartj/ehn482

54. Yanagisawa M, Kurihara H, Kimura S, Tomobe Y, Kobayashi M, Mitsui Y, et al. A novel potent vasoconstrictor peptide produced by vascular endothelial cells. Nature. (1988) 332:411-5. doi: 10.1038/332411a0

55. Viljoen M, Koorts AM. A role for proinflammatory cytokines in the behavioral disturbances and cognitive decline in chronic renal failure patients. Clin Nephrol. (2004) 61:227-9. doi: 10.5414/CNP61227

56. Hirata Y, Kanno K, Watanabe TX, Kumagaye S, Nakajima K, Kimura T, et al. Receptor binding and vasoconstrictor activity of big endothelin. Eur $J$ Pharmacol. (1990) 176:225-8. doi: 10.1016/0014-2999(90)90532-B

57. Rubens C, Ewert R, Halank M, Wensel R, Orzechowski HD, Schultheiss HP, et al. Big endothelin-1 and endothelin-1 plasma levels are correlated with the severity of primary pulmonary hypertension. Chest. (2001) 120:15629. doi: 10.1378/chest.120.5.1562

58. Meoli DF, Su YR, Brittain EL, Robbins IM, Hemnes AR, Monahan $\mathrm{K}$. The transpulmonary ratio of endothelin 1 is elevated in patients with preserved left ventricular ejection fraction and combined pre- and post-capillary pulmonary hypertension. Pulm $\begin{array}{llll}\text { Circ. (2018) 8:2045893217745019. doi: 10.1177/20458932177 } & \end{array}$ 45019

59. Chowdhury MA, Moukarbel GV, Gupta R, Frank SM, Anderson AM, Liu LC, et al. Endothelin 1 is associated with heart failure hospitalization and long-term mortality in patients with heart failure with preserved 
ejection fraction and pulmonary hypertension. Cardiology. (2019) 143:12433. doi: $10.1159 / 000501100$

60. Koller B, Steringer-Mascherbauer R, Ebner CH, Weber T, Ammer M, Eichinger J, et al. Pilot study of endothelin receptor blockade in heart failure with diastolic dysfunction and pulmonary hypertension (BADDHY-Trial). Heart Lung Circ. (2017) 26:433-41. doi: 10.1016/j.hlc.2016. 09.004

61. Kaluski E, Cotter G, Leitman M, Milo-Cotter O, Krakover R, Kobrin I, et al. Clinical and hemodynamic effects of bosentan dose optimization in symptomatic heart failure patients with severe systolic dysfunction, associated with secondary pulmonary hypertension-a multi-center randomized study. Cardiology. (2008) 109:273-80. doi: 10.1159/000107791

62. Vachiéry J-L, Delcroix M, Al-Hiti H, Efficace M, Hutyra M, Lack G, et al. Macitentan in pulmonary hypertension due to left ventricular dysfunction. Eur Resp J. (2018) 51:1701886. doi: 10.1183/13993003.01886-2017

63. Achen MG, Jeltsch M, Kukk E, Mäkinen T, Vitali A, Wilks AF, et al. Vascular endothelial growth factor D (VEGF-D) is a ligand for the tyrosine kinases VEGF receptor 2 (Flk1) and VEGF receptor 3 (Flt4). Proc Natl Acad Sci USA. (1998) 95:548-53. doi: 10.1073/pnas.95.2.548

64. Rissanen TT, Markkanen JE, Gruchala M, Heikura T, Puranen A, Kettunen MI, et al. VEGF-D Is the strongest angiogenic and lymphangiogenic effector among VEGFs delivered into skeletal muscle via adenoviruses. Circul Res. (2003) 92:1098-106. doi: 10.1161/01.RES.0000073584.46059.E3

65. Zhao T, Zhao W, Meng W, Liu C, Chen Y, Bhattacharya SK, et al. Vascular endothelial growth factor-D mediates fibrogenic response in myofibroblasts. Mol Cell Biochem. (2016) 413:127-35. doi: 10.1007/s11010-015-2646-1

66. Chen H, Guan R, Lei Y, Chen J, Ge Q, Zhang X, et al. Lymphangiogenesis in gastric cancer regulated through Akt/mTOR-VEGF-C/VEGF-D axis. BMC Cancer. (2015) 15:103. doi: 10.1186/s12885-015-1109-0

67. Rutanen J, Rissanen TT, Markkanen JE, Gruchala M, Silvennoinen P, Kivela A, et al. Adenoviral catheter-mediated intramyocardial gene transfer using the mature form of vascular endothelial growth factor-D induces transmural angiogenesis in porcine heart. Circulation. (2004) 109:102935. doi: 10.1161/01.CIR.0000115519.03688.A2

68. Hartikainen J, Hassinen I, Hedman A, Kivela A, Saraste A, Knuuti J, et al. Adenoviral intramyocardial VEGF-DDeltaNDeltaC gene transfer increases myocardial perfusion reserve in refractory angina patients: a phase I/IIa study with 1-year follow-up. Eur Heart J. (2017) 38:254755. doi: 10.1093/eurheartj/ehx352

69. Berntsson J, Smith JG, Johnson LSB, Soderholm M, Borne Y, Melander $\mathrm{O}$, et al. Increased vascular endothelial growth factor $\mathrm{D}$ is associated with atrial fibrillation and ischaemic stroke. Heart. (2019) 105:5538. doi: 10.1136/heartjnl-2018-313684

70. Borne Y, Gransbo K, Nilsson J, Melander O, Orho-Melander M, Smith JG, et al. Vascular endothelial growth factor D, pulmonary congestion, and incidence of heart failure. J Am Coll Cardiol. (2018) 71:5802. doi: 10.1016/j.jacc.2017.11.058

71. Saleby J, Bouzina H, Lundgren J, Radegran G. Angiogenic and inflammatory biomarkers in the differentiation of pulmonary hypertension. Scand Cardiovasc J. (2017) 51:261-70. doi: 10.1080/14017431.2017.1359419

72. Saleby J, Bouzina H, Ahmed S, Lundgren J, Radegran G. Plasma receptor tyrosine kinase RET in pulmonary arterial hypertension diagnosis and differentiation. ERJ Open Res. (2019) 5:00037-2019. doi: 10.1183/23120541.00037-2019

73. Seyama K, Kumasaka T, Souma S, Sato T, Kurihara M, Mitani K, et al. Vascular endothelial growth factor-D is increased in serum of patients with lymphangioleiomyomatosis. Lymphat Res Biol. (2006) 4:14352. doi: $10.1089 / \mathrm{lrb} .2006 .4 .143$

74. Wada H, Suzuki M, Matsuda M, Ajiro Y, Shinozaki T, Sakagami S, et al. Distinct characteristics of VEGF-D and VEGF-C to predict mortality in patients with suspected or known coronary artery disease. J Am Heart Assoc. (2020) 9:e015761. doi: 10.1161/JAHA.119.015761

75. Houston BA, Tedford RJ, Baxley RL, Sykes B, Powers ER, Nielsen CD, et al. Relation of lymphangiogenic factor vascular endothelial growth factor-D to elevated pulmonary artery wedge pressure. Am J Cardiol. (2019) 124:75662. doi: 10.1016/j.amjcard.2019.05.056

76. Al-Husseini A, Kraskauskas D, Mezzaroma E, Nordio A, Farkas D, Drake JI, et al. Vascular endothelial growth factor receptor 3 signaling contributes to angioobliterative pulmonary hypertension. Pulm Circul. (2015) 5:10116. doi: $10.1086 / 679704$

77. Grasedieck S, Scholer N, Bommer M, Niess JH, Tumani H, Rouhi A, et al. Impact of serum storage conditions on microRNA stability. Leukemia. (2012) 26:2414-6. doi: 10.1038/leu.2012.106

78. Wong LL, Wang J, Liew OW, Richards AM, Chen YT. MicroRNA and heart failure. Int J Mol Sci. (2016) 17:502. doi: 10.3390/ijms17040502

79. Boucherat O, Potus F, Bonnet S. microRNA and pulmonary hypertension. Adv Exp Med Biol. (2015) 888:237-52. doi: 10.1007/978-3-319-22671-2_12

80. Estephan LE, Genuardi MV, Kosanovich CM, Risbano MG, Zhang $\mathrm{Y}$, Petro N, et al. Distinct plasma gradients of microRNA-204 in the pulmonary circulation of patients suffering from WHO groups I and II pulmonary hypertension. Pulm Circ. (2019) 9:2045894019840646. doi: 10.1177/2045894019840646

81. Yue J, Guan J, Wang X, Zhang L, Yang Z, Ao Q, et al. MicroRNA206 is involved in hypoxia-induced pulmonary hypertension through targeting of the HIF-1alpha/Fhl-1 pathway. Lab Invest. (2013) 93:74859. doi: 10.1038/labinvest.2013.63

82. Jalali S, Ramanathan GK, Parthasarathy PT, Aljubran S, Galam L, Yunus A, et al. Mir-206 regulates pulmonary artery smooth muscle cell proliferation and differentiation. PLOS ONE. (2012) 7:e46808. doi: 10.1371/journal.pone.0046808

83. Sharma S, Umar S, Centala A, Eghbali M. Role of miR206 in genistein-induced rescue of pulmonary hypertension in monocrotaline model. J Appl Physiol (1985). (2015) 119:1374-82. doi: 10.1152/japplphysiol.00699.2014

84. Yang Y, Del Re DP, Nakano N, Sciarretta S, Zhai P, Park J, et al. miR-206 mediates YAP-induced cardiac hypertrophy and survival. Circ Res. (2015) 117:891-904. doi: 10.1161/CIRCRESAHA.115.306624

85. Mirna M, Rohm I, Jirak P, Wernly B, Baz L, Paar V, et al. Analysis of novel cardiovascular biomarkers in patients with Pulmonary Hypertension (PH). Heart Lung Circ. (2020) 29:337-44. doi: 10.1016/j.hlc.2019.03.004

86. Luedike P, Alatzides G, Papathanasiou M, Heisler M, Pohl J, Lehmann N, et al. Predictive potential of macrophage migration inhibitory factor (MIF) in patients with heart failure with preserved ejection fraction (HFpEF). Eur J Med Res. (2018) 23:22. doi: 10.1186/s40001-018-0321-1

87. DuBrock HM, AbouEzzeddine OF, Redfield MM. High-sensitivity C-reactive protein in heart failure with preserved ejection fraction. PLoS ONE. (2018) 13:e0201836. doi: 10.1371/journal.pone.0201836

88. Nguyen QL, Wang Y, Helbling N, Simon MA, Shiva S. Alterations in platelet bioenergetics in Group 2 PH-HFpEF patients. PLoS ONE. (2019) 14:e0220490. doi: 10.1371/journal.pone.0220490

89. Ranchoux B, Nadeau V, Bourgeois A, Provencher S, Tremblay E, Omura J, et al. Metabolic syndrome exacerbates pulmonary hypertension due to left heart disease. Circ Res. (2019) 125:44966. doi: 10.1161/CIRCRESAHA.118.314555

90. Lai YC, Tabima DM, Dube JJ, Hughan KS, Vanderpool RR, Goncharov DA, et al. SIRT3-AMP-activated protein kinase activation by nitrite and metformin improves hyperglycemia and normalizes pulmonary hypertension associated with heart failure with preserved ejection fraction. Circulation. (2016) 133:717-31. doi: 10.1161/CIRCULATIONAHA.115.018935

91. Brittain EL, Talati M, Fortune N, Agrawal V, Meoli DF, West J, et al. Adverse physiologic effects of Western diet on right ventricular structure and function: role of lipid accumulation and metabolic therapy. Pulm Circ. (2019) 9:2045894018817741. doi: 10.1177/2045894018817741

92. Simon MA, Vanderpool RR, Nouraie M, Bachman TN, White PM, Sugahara $\mathrm{M}$, et al. Acute hemodynamic effects of inhaled sodium nitrite in pulmonary hypertension associated with heart failure with preserved ejection fraction. JCI Insight. (2016) 1:e89620. doi: 10.1172/jci.insight.89620

93. Zhuang R, Wu J, Lin F, Han L, Liang X, Meng Q, et al. Fasudil preserves lung endothelial function and reduces pulmonary vascular remodeling in a rat model of endstage pulmonary hypertension with left heart disease. Int $J$ Mol Med. (2018) 42:1341-52. doi: 10.3892/ijmm.2018.3728

94. Zhang X, Zhang X, Wang S, Luo J, Zhao Z, Zheng C, et al. Effects of fasudil on patients with pulmonary hypertension associated with left ventricular heart failure with preserved ejection fraction: a prospective intervention study. Can Respir J. (2018) 2018:3148259. doi: 10.1155/2018/3148259

95. Hemnes AR, Beck GJ, Newman JH, Abidov A, Aldred MA, Barnard J, et al. PVDOMICS: a multi-center study to improve understanding of 
pulmonary vascular disease through phenomics. Circ Res. (2017) 121:11369. doi: 10.1161/CIRCRESAHA.117.311737

96. Shah SJ, Borlaug BA, Kitzman DW, McCulloch AD, Blaxall BC, Agarwal $\mathrm{R}$, et al. Research priorities for heart failure with preserved ejection fraction: national heart, lung, and blood institute working group summary. Circulation. (2020) 141:1001-26. doi: 10.1161/CIRCULATIONAHA.119. 041886

97. Nickel NP, Yuan K, Dorfmuller P, Provencher S, Lai YC, Bonnet $\mathrm{S}$, et al. Beyond the lungs: systemic manifestations of pulmonary arterial hypertension. Am J Respir Crit Care Med. (2020) 201:14857. doi: $10.1164 / \mathrm{rccm} .201903-0656 \mathrm{CI}$
Conflict of Interest: The authors declare that the research was conducted in the absence of any commercial or financial relationships that could be construed as a potential conflict of interest.

Copyright $\odot 2020$ Todd and Lai. This is an open-access article distributed under the terms of the Creative Commons Attribution License (CC BY). The use, distribution or reproduction in other forums is permitted, provided the original author(s) and the copyright owner(s) are credited and that the original publication in this journal is cited, in accordance with accepted academic practice. No use, distribution or reproduction is permitted which does not comply with these terms. 